\title{
The effects of aging on the distribution of cerebral blood flow with postural changes and mild hyperthermia
}

\author{
Akemi Ota, Ryosuke Takeda, Daiki Imai, Nooshin Naghavi, Eriko \\ Kawai, Kosuke Saho, Emiko Morita, Yuta Suzuki, Hisayo \\ Yokoyama, Toshiaki Miyagawa, Kazunobu Okazaki
}

\begin{tabular}{|c|l|}
\hline Citation & European Journal of Applied Physiology, 119(5); 1261-1272 \\
\hline Issue Date & $2019-05-01$ \\
\hline Type & Journal article \\
\hline Textversion & Authors \\
\hline Rights & $\begin{array}{l}\text { This is a post-peer-review, pre-copyedit version of an article published in European } \\
\text { Journal of Applied Physiology. The final authenticated version is available online at: } \\
\text { https://doi.org/10.1007/s00421-019-04118-5. } \\
\text { Springer Nature terms of use: } \\
\text { https://www.springer.com/gp/open-access/publication-policies/aam-terms-of-use. }\end{array}$ \\
\hline DOI & $10.1007 /$ s00421-019-04118-5 \\
\hline
\end{tabular}

\author{
Self-Archiving by Author(s) \\ Placed on: Osaka City University
}

OTA, A., et al. (2019). The effects of aging on the distribution of cerebral blood flow with postural changes and mild hyperthermia. European Journal of Applied Physiology. 119, 1261-1272. doi:10.1007/s00421-019-04118-5 
1 The effects of aging on the distribution of cerebral blood flow with postural changes and 2 mild hyperthermia

3

4 Akemi Ota ${ }^{1,2}$, Ryosuke Takeda ${ }^{3}$, Daiki Imai ${ }^{1,3}$, Nooshin Naghavi ${ }^{1}$, Eriko Kawai ${ }^{1}$, Kosuke Saho ${ }^{1}$,

5 Emiko Morita ${ }^{1}$, Yuta Suzuki ${ }^{1,3}$, Hisayo Yokoyama ${ }^{1,3}$, Toshiaki Miyagawa ${ }^{1,3}$, and Kazunobu

$6 \quad$ Okazaki $^{1,3}$

$7 \quad{ }^{1}$ Department of Environmental Physiology for Exercise, Osaka City University Graduate School

8 of Medicine, Osaka, Japan, ${ }^{2}$ Department of Health Promotion and Sports Sciences, Osaka

9 Electro-communication University, Osaka, Japan, ${ }^{3}$ Research Center for Urban Health and Sports,

10 Osaka City University, Osaka, Japan

11

12 Running head: Age, heat, and orthostatic stress on intracranial blood flow

Word count: 5203

Tables: 3

Figures: 2

\section{Corresponding author}

17 Kazunobu Okazaki, Ph.D.

Research Center for Urban Health and Sport, Osaka City University, and Department of

19 Environmental Physiology for Exercise, Osaka City University Graduate School of Medicine, 3-

20 3-138 Sugimoto Sumiyoshi, Osaka 558-8585, Japan

21 TEL: +81-6-6605-2950 / FAX: +81-6-6605-2950

22 E-mail: okazaki@sports.osaka-cu.ac.jp

24 Conflict of Interest: None declared. 
ABSTRACT

27 Purpose: Cerebral blood flow (CBF) would be impaired with dual stresses of heat and orthostatic changes, even if those stresses are mild, in the elderly with declined cardio- and cerebrovascular functions with ageing. To test the hypothesis, we compared the response of blood flow in the internal carotid artery (ICA) and vertebral artery (VA) to dual stresses of heat and orthostatic changes between the elderly and young individuals.

Methods: Nine elderly and eight young healthy men $(71.3 \pm 3.0$ and $23.3 \pm 3.1$ years, mean \pm SD, respectively) underwent measurements of blood flow in the ICA, VA and external carotid artery (ECA) via ultrasonography. The measurements were obtained in sitting and supine positions under normothermic (NT) and mildly hyperthermic (HT) conditions (ambient temperature $\left.28^{\circ} \mathrm{C}\right)$. Esophageal temperatures increased from $\mathrm{NT}\left(36.4 \pm 0.2^{\circ} \mathrm{C}\right.$, mean $\left.\pm \mathrm{SE}\right)$ to HT $\left(37.4 \pm 0.2^{\circ} \mathrm{C}\right)$ with lower legs immersion in $42^{\circ} \mathrm{C}$ water.

Results: With heat stress, ECA blood flow increased in both postures in both age groups (effect of heat, $\mathrm{p}<0.001$ ), whereas ICA blood flow remained unchanged. With postural changes from supine to sitting, ECA blood flow remained unchanged whereas ICA blood flow decreased (effect of posture, $\mathrm{p}=0.027$ ) by $18 \%$ in NT in the young and by $20 \%$ in HT in the elderly. VA blood flow remained unchanged under both heat stress and postural changes.

Conclusions: The CBF is impaired under dual stresses of heat and orthostatic changes in healthy aged individuals, even if the levels of the stresses are mild.

Keywords: carotid artery, orthostatic stress, heat stress, elderly 
Abbreviations

\begin{tabular}{|l|l|}
\hline CBF & Cerebral blood flow \\
\hline ECA & External carotid artery \\
\hline ICA & Internal carotid artery \\
\hline VA & Vertebral artery \\
\hline CO & Cardiac output \\
\hline MCAv & Middle cerebral artery \\
\hline SV & Stroke volume \\
\hline$T_{\text {es }}$ & Esophageal temperature \\
\hline HR & Heart rate \\
\hline NT & Normothermia \\
\hline HT & Hyperthermia \\
\hline$T_{\text {sk }}$ & Skin temperature \\
\hline PP & Pulse pressure \\
\hline MBP & Mean blood pressure \\
\hline BP & Slood pressure \\
\hline PETCO $_{2}$ & Standard deviation \\
\hline MRI & \\
\hline ANOVA & \\
\hline
\end{tabular}




\section{INTRODUCTION}

51 Whether individually or experienced in combination, orthostatic stress and heat stress can greatly impact daily living in young and older individuals. Previous studies have reported that both of the orthostatic stress (Alperin et al. 2005; Ogoh et al. 2015; Sato et al. 2012) and passive whole body heating (Brothers et al. 2009; Lind et al. 1968; Low et al. 2008; Nakata et al. 2017; Wilson et al. 2006; Wilson et al. 2002) decrease cerebral blood flow (CBF) even in healthy young adults. With orthostatic stress, decrease in cardiac output (CO) (Meng et al. 2015; Ogoh et al. 2005), hypocapnia with hyperventilation and modified carbon dioxide $\left(\mathrm{CO}_{2}\right)$ reactivity (Serrador et al. 2006) or deterioration of cerebral autoregulation (Zhang et al. 1998) have been reported as a possible mechanism of the decreased CBF. In fact, the mean total CBF, measured with time-offlight and cine phase-contrast magnetic resonance imaging (MRI) techniques, was $12 \%$ lower in the sitting position compared with the supine position (Alperin et al. 2005). Other studies that assessed blood flow in neck arteries with the Doppler ultrasonography as a quantitative measure of CBF demonstrated that the internal carotid artery (ICA) blood flow, which forms the anterior cerebral circulation and nourishes a large portion of the anterior brain, declined with orthostatic stress by using head-up tilt (Sato et al. 2012) or lower body negative pressures (Ogoh et al. 2015). In contrast, the vertebral artery (VA) blood flow, which merges into the basilar artery and nourishes the posterior part of the brain, brainstem, cerebellum and spinal cord, remained unchanged, indicating the importance of quantitative assessment of blood flow in neck arteries.

On the other hand, the decreased CBF with passive whole body heating (Lind et al. 1968; Low et al. 2008; Nakata et al. 2017; Wilson et al. 2006; Wilson et al. 2002) is associated primarily with heat dissipating mechanisms, including augmented cutaneous vasodilation and sweating, together with peripheral blood pooling and dehydration, could induce reduction in the central blood volume and arterial blood pressure (BP), although CO rises under heat stress (Crandall et al. 1999). Furthermore, it has been reported that the decreased CBF under hyperthermic conditions is 
Nelson et al. 2011) and modified $\mathrm{CO}_{2}$ reactively (Wilson et al. 2006). Indeed, Bain et al., (Bain et al. 2013) reported that hyperventilation induced decrease in the partial pressure of end-tidal $\mathrm{CO}_{2}$ $\left(\mathrm{P}_{\mathrm{ET}} \mathrm{CO}_{2}\right)$ during severe hyperthermia $\left(+2.0^{\circ} \mathrm{C}\right.$ above resting) predominated any decrease in blood flow on the encephalic vasculatures whilst supine. Conversely, it has been indicated that $\mathrm{P}_{\mathrm{ET}} \mathrm{CO}_{2}$ accounted for the CBF reduction to a smaller extent during mild hyperthermia $\left(\sim 1.2^{\circ} \mathrm{C}\right.$ above resting) than severe hyperthermia (Brothers et al. 2009; Nelson et al. 2011) and that reduced venous return to the heart and stroke volume (SV) is primarily associated with the CBF reduction. Reportedly, the ICA blood flow is decreased by about $15 \%$ with each $\sim 1.2^{\circ} \mathrm{C}$ increase in the core temperature when subjects are in the supine position (Nakata et al. 2017). More specifically, it has been shown that the ICA and VA blood flow decreased with an increased esophageal temperature ( $\mathrm{T}_{\mathrm{es}}$ ) in passively heated young subjects (Ogoh et al. 2013b). Such cerebral hypoperfusion is a factor leading to light-headedness, dizziness, nausea, and syncope, which could impair cerebral oxygenation (Van Lieshout et al. 2003) and act as a factor resulting in cognitive dysfunction (Nakata et al. 2015; Shibasaki et al. 2017).

The CBF is also known to decrease with advancing age (Ainslie et al. 2008; Amin-Hanjani et al. 2015; Bain et al. 2015; Parkes et al. 2004; Tarumi et al. 2014). Age-related changes in the cardio- and cerebrovascular systems, including central artery stiffness (Tarumi et al. 2014), general widening and hardening of arterioles and venules (Lakatta 1993a; Sonntag et al. 2007; Vaitkevicius et al. 1993), declined $\mathrm{PaCO}_{2}$ though cerebrovascular $\mathrm{CO}_{2}$ reactivity does not seemingly change (Bronzwaer et al. 2017), and decreased CO (Lakatta 1993b) are likely related to the age-associated decreases in the CBF, although autoregulation appears to be intact amongst healthy elderly individuals (Oudegeest-Sander et al. 2014). Of note, reduced CBF is a possible risk factor for the pathogenesis of white matter damage (Tarumi et al. 2014) and cognitive decline in the elderly (Benedictus et al. 2017). Moreover, cardiovascular responsiveness to heat (Minson et al. 1998) and orthostatic stresses (Lucas et al. 2008) including elevation in heart rate (HR) are generally reduced even in healthy individuals because of the attenuated increase in the autonomic 
outflow and beta-responsiveness (Lakatta 1993b). Considering the significance of the sensitivity

103 to $\mathrm{CO}_{2}$ of brain vasculatures and the age related decline in $\mathrm{PaCO}_{2}$ (Bronzwaer et al. 2017), the

104 elderly populations may be especially susceptible to disorders caused by cerebral hypoperfusion

105 during the orthostatic challenge, especially under hyperthermia. Lucas et al. (Lucas et al. 2008)

106 reported that blood flow velocity in the middle cerebral artery (MCAv) at the baseline in the

107 supine normothermic state was lower than the standing state, and the drop in MCAv from supine

108 to standing in normothermia was greater in elderly adults than in young adults. Nevertheless, an

109 increase in $\mathrm{T}_{\text {es }}$ of $0.5^{\circ} \mathrm{C}$ using a water-perfused suit did not exacerbate the postural response in

110 either age group. However, the CBF was not assessed volumetrically but estimated with blood

111 flow velocity of the cerebral artery by using transcranial Doppler ultrasonography in their study.

112 To date, no studies have examined the possibility that the CBF in elderly individuals is impaired

113 under the dual stresses of heat and orthostasis, even when those stresses are mild, and when each

114 stress alone would not induce substantial changes in CBF.

115 The purpose of this study was to assess the effects of healthy aging on the distribution of CBF.

116 To accomplish this, we assessed blood flows through the ICA and VA, two arteries that supply a

117 large portion of the anterior and posterior brain, respectively, under two conditions: 1) postural

118 change from the supine to sitting position and 2) during normothermia (NT) and mild

119 hyperthermia (HT). We hypothesized that the CBF in elderly subjects would be impaired under

120 the dual stresses of postural change and mild hyperthermia.

\section{METHODS}

\section{Subjects}

124 Nine elderly and eight young male volunteers participated in this study. The characteristics of

125 the subjects are shown in Table 1 . All subjects were non-smokers and had no overt history of 126 cardiovascular, metabolic, or pulmonary diseases. The mean age was greater and mean height was shorter in the elderly subjects compared to those of the young subjects. However, there were no 
significant differences in body weight and body mass index between the groups. The subjects were active, but were not engaged in any regular exercise training protocol except for daily walking. Each subject provided written informed consent before participation in the study, which was approved by the Institutional Review Board of Osaka City University Graduate School of Medicine (No. 2711) and conformed to the standards set by the Declaration of Helsinki. All experiments were performed in cool seasons (other than July, August, and September) in Japan.

\section{Experimental protocol}

Subjects were requested to abstain from consuming caffeinated or alcoholic beverages and to refrain from vigorous physical activity for 24 hours before the experiment. Subjects arrived at the laboratory having fasted for at least 2 hours after a light meal and at least 1 hour after drinking $500 \mathrm{~mL}$ of water to avoid dehydration. The subjects were instructed to void, were weighed in the nude, and were asked to put on short pants. They then inserted an esophageal thermistor through the external nares to measure $\mathrm{T}_{\text {es. }}$. Thermistor probes were also applied to the skin surfaces to measure skin temperatures. The tip of the esophageal thermistor was advanced to a distance that was one-fourth the participant's standing height. Experiments were performed in a climatic chamber (TBR-6W2S2L2M; ESPEC Co., Osaka, Japan) with an ambient temperature of $28.0 \pm$ $0.1^{\circ} \mathrm{C}$ (mean \pm range) and a relative humidity of $40 \pm 1 \%$. The subjects sat on a reclining chair in the chamber for 20 minutes during instrumentation, and then baseline data were collected in the sitting position.

Figure 1 shows the experimental protocol and the posture of subjects. The subjects underwent the measurements in the sitting or supine position with the order counterbalanced under the thermoneutral condition as normothermia (NT). The backrest angle of the reclining chair was adjusted to $0^{\circ}$ for the supine position and $70^{\circ}$ for the sitting position. CBF data were obtained after a 5-minute equilibrium period in the appropriate body position. Thermal and hemodynamic data were collected for 5 minutes in each condition. All of the procedures were performed again 
in the alternate body position. After measurements were obtained in NT, the subjects were passively heated in the sitting position by placing their lower legs in water that was controlled at $42^{\circ} \mathrm{C}$. After 40 minutes of heating, the same measurements were obtained under the mild hyperthermia (HT) same as during NT while keeping passive heating.

\section{Measurements}

Thermometry:

$\mathrm{T}_{\text {es }}$ was measured with the esophageal thermistor inserted into a polyethylene tube (LT-ST0811; Gram Co, Saitama, Japan). Skin surface temperatures were measured using thermistors (LTST08-12; Gram Co) placed on skin surface of the right side of the chest, upper arm, thigh, and leg. Data for $\mathrm{T}_{\mathrm{es}}$ and skin temperatures were collected at intervals of $1 \mathrm{sec}$. The mean skin temperature $\left(T_{\mathrm{sk}}\right)$ was calculated as the weighted average signified by $0.3 \times$ (chest temperature + upper arm temperature) $+0.2 \times$ (thigh temperature + leg temperature) (Ramanathan 1964).

Cardiovascular responses:

HR were obtained from electrocardiogram tracings (BSM-7201; Nihon Kohden Co., Tokyo, Japan). Intermittent arterial blood pressures were measured every minute by auscultation of the brachial artery via electrosphygmomanometry (STBP-780, Colin, Komaki, Japan). Pulse pressure (PP) was calculated as systolic BP - diastolic BP and mean blood pressure (MBP) was calculated as $\mathrm{DBP}+\mathrm{PP} / 3$. The partial pressure of end-tidal carbon dioxide $\left(\mathrm{P}_{\mathrm{ET}} \mathrm{CO}_{2}\right)$ was monitored by a carbon dioxide monitor with a nasal adaptor (OLG-2800, Nihon, Tokyo, Japan).

CBF:

Blood flow in the left side of ICA, external carotid artery (ECA) and VA were measured using a color-coded ultrasound system (Vivid-i; GE Healthcare, Tokyo, Japan) equipped with a $12 \mathrm{MHz}$ linear transducer. The ICA blood flow was measured $~ 1.0-1.5 \mathrm{~cm}$ distal to the carotid bifurcation 
while the subjects' chin was slightly elevated. The ECA blood flow was measured $\sim 1.0-1.5 \mathrm{~cm}$

181 above the carotid bifurcation, or immediately before the first ECA branch. The VA blood flow

182 was measured between the transverse processes of the C3 and the subclavian artery. For blood

183 flow measurements, the brightness mode was first used in a longitudinal section to measure the

184 mean diameter of each vessel. Next, the flow velocity spectra by pulsed wave Doppler were

185 recorded for 16 sec to estimate the time averaged flow velocity. Throughout insonation, care was

186 taken to ensure that the probe position was stable, the insonation angle did not vary (60 degrees in most cases), that the sample volume was positioned in the center of the vessel, and the position was adjusted to cover the width of the vessel diameter. When a subject moved or the insonation angle of the ultrasound beam changed during recording, the operator extended the data recording duration to obtain reliable images for the whole frame of the recording period. The systolic and diastolic diameters were measured for an average of 3 cardiac cycles, then the mean diameters (cm) were calculated using the formula as follows:

Mean diameter $=[($ systolic diameter $\times 1 / 3)]+[($ diastolic diameter $\times 2 / 3)]($ Ogoh et al. 2013a $)$. average of $\sim 8$ to 25 cardiac cycles to eliminate the breathing cycle effects. Finally, blood flow was calculated as a product of the mean blood flow velocity and cross-sectional area as follows: (Ogoh et al. 2013a).

All ultrasound measurements were performed by a trained investigator. Although care was taken during each insonation, the subjects' postures and the increased ventilation with heat stress made it difficult to obtain reliable images in some subjects. Therefore, the sample size used for comparison of blood flow in the VA was five in the elderly group. 

$\mathrm{T}_{\mathrm{es}}, \mathrm{T}_{\mathrm{sk}}, \mathrm{BP}$, and $\mathrm{HR}$ at each condition were averaged for $5 \mathrm{~min}$. Arterial conductance in the ICA, VA, and ECA were calculated as the blood flow at each site divided by MBP corrected by the hydrostatic pressure difference between the level of the cuff and measurement sites.

Statistical analysis

211 We used three-factor repeated-measures ANOVA (two factors, heat and posture, repetition) to assess the effects of heat (NT vs. HT), posture (supine vs. sitting), and age (young vs. elderly) on each variable (inter-subject factor: age; intra-subject factors: heat and posture). Subsequent posthoc tests to determine significant differences in each pairwise comparison were performed using the Scheffe test. All data were analyzed using SPSS statistical software (SPSS version 17.0, SPSS Inc., Chicago, IL). Statistical significance was established at an $\alpha$ level of 0.05 , and values are expressed as means \pm SEM.

\section{RESULTS}

No participants expressed any presyncopal symptoms during the experiment. The body temperatures and cardiovascular responses are presented in Table 2. There was no significant effect of age on any variable, except for $\mathrm{P}_{\mathrm{ET}} \mathrm{CO}_{2}$ which exhibited lower values in the elderly group than in the young group (effect of age, $\mathrm{p}<0.001$ ). $\mathrm{T}_{\mathrm{es}}$, and $\mathrm{T}_{\mathrm{sk}}$ increased with passive heating in both body postures and age groups (effect of heat, both, $\mathrm{p}<0.001$ ). We also found significant effects of posture on $\mathrm{T}_{\text {es }}$ and $\mathrm{T}_{\mathrm{sk}}\left(\mathrm{p}=0.001\right.$ and $\mathrm{p}=0.018$, respectively). $\mathrm{T}_{\text {es }}$ was significantly higher in the sitting than in the supine position during NT in both groups and during HT in the young group. $T_{\mathrm{sk}}$ showed significantly lower values in the sitting than in the supine position during HT in both groups.

HR increased with heat stress in both body postures and age groups (effect of heat, $\mathrm{p}<0.001$ ). In contrast, there were significant effects on posture $(\mathrm{p}=0.005)$ and interactions (posture $\times$ age, $p=0.002$ ) with HR. Importantly HR increased significantly in the sitting compared to the supine 
position in the young, but not in the elderly group. Also, there were significant effects of interaction on DBP and MBP (posture $\times$ age, $\mathrm{p}=0.018$ and 0.028, respectively). $\mathrm{P}_{\mathrm{ET}} \mathrm{CO}_{2}$ decreased with heat stress and with orthostatic stress in the young group, whereas it declined only with orthostatic stress during HT in the elderly group.

Figure 2 shows the blood flow in the neck arteries in each condition and Table 3 presents the mean blood flow velocity and mean vessel diameter with conductance. With heat stress, ECA blood flow increased in both body postures and age groups (effect of heat, $\mathrm{p}<0.001$ ) whereas ICA blood flow remained unchanged. However, with the postural change from supine to sitting, ECA blood flow remained unchanged whereas ICA blood flow decreased (effect of posture, $p=$ 0.027) significantly in NT in the young group, whereas it decreased in HT in the elderly group. We found significant effect of interaction (heat $\times$ posture $\times$ age, $p=0.027$; heat $\times$ age, $p=0.021$ ) on ICA blood flow. VA blood flow remained unchanged under heat stress and postural change. In addition, the mean blood flow velocity for ICA and VA remained unchanged with heat stress and postural change in both age groups, whereas it increased for ECA with heat stress in both body postures and age groups (effect of heat, $\mathrm{p}<0.001$ ). The mean blood flow velocity for VA was lower in the elderly than in the young group (effect of age, $p=0.001$ ). The mean vessel diameter declined with the postural change from supine to sitting for ICA during HT in the elderly group and during NT in the young group (effect of posture, $\mathrm{p}=0.048$. Also, the mean vessel diameter declined with the postural change from supine to sitting for ECA during HT in both age groups (effect of posture, $p=0.035$ ). We found a significant effect of interaction (heat $\times$ age, $p=0.046$ ) on the mean vessel diameter in the ICA. Furthermore, we found a significant effect of age on the conductance of the ECA ( $p=0.018)$. Heat stress increased the conductance of the ECA in both body postures and age groups (effect of heat, $\mathrm{p}<0.001$ ). We also found a significant effect of interaction (heat $\times$ posture $\times$ age, $p=0.025$ ) on the conductance of the ICA.

\section{DISCUSSION}


The major findings in the present study were that the ICA blood flow declined markedly in the sitting position compared with the supine position during mild hyperthermia in the elderly group and during normothermia in the young group. Therefore, the CBF in aged but healthy individuals is impaired during exposure to dual stresses of heat and orthostatic changes, even if the level of each stress is mild and might not have induced substantial changes in the CBF as single stressors. Hence, the elderly populations could be at a potential risk for cerebral hypoperfusion in the situation with orthostatic challenge and heat stress during their daily living.

To date, limited studies have reported the effects of normal aging on the response of CBF to dual stresses, including heat and orthostatic changes, although many previous studies have reported CBF responses to heat stress and/or orthostatic stress in young adults. One previously study by Lucas et al. (Lucas et al. 2008) reported the effects of normal aging on the CBF response assessed by the MCAv during the dual stresses of hyperthermia and orthostatic changes. They observed that the decline in MCAv when changing from a supine position to standing in normothermic conditions was greater in older adults than in young adults. However, an increase in $\mathrm{T}_{\mathrm{es}}$ of $0.5^{\circ} \mathrm{C}$ using a water-perfused suit did not exacerbate the postural responses in either age group (Lucas et al. 2008). In the present study, we observed that the ICA blood flow in elderly adults remained unchanged under the single stress of a postural change from supine to sitting or in mildly hyperthermic conditions, whereas it was impaired with the simultaneous application of those two stresses (Figure 2). The inconsistency of observations between the previous study and our study could be attributed primarily to differences in the methodology of CBF measurement. In the previous study, the CBF was estimated by blood flow velocity of the middle cerebral artery by using transcranial Doppler ultrasonography without vessel diameter and quantitative blood flow assessment. In the present study, we assessed blood flows through the ICA and VA for the volumetrically assessment of the CBF via ultrasonography. Additionally, the inconsistency could also be associated with differences in the time periods and levels of orthostatic stress and hyperthermia between studies. In the previous study, the orthostatic stress (3 minutes standing 
from the supine position) was acute and lasted for a shorter period of time while higher for level compared with our study to induce a significant reduction in the CBF with standing, even during normothermic conditions in both age groups (Lucas et al. 2008). Meanwhile the level of heat stress in the previous study was lower than that in our study and would not have been high enough to induce a significant effect on the CBF response in conjunction with the orthostatic stress (Lucas et al. 2008).

The attenuated increase in HR in response to the orthostatic stress could be a possible mechanism in the reduction of ICA blood flow during the dual stresses of orthostatic change and hyperthermia observed in the elderly group (Figure 2). In fact, the increase in HR with orthostatic stress in the elderly group was totally abolished and substantially lower than in the young group as we observed a significant effect of interaction (posture $\times$ age) in HR. An attenuated betaresponsiveness of the heart (Lakatta 1993b) and an attenuated increase in autonomic outflow to orthostatic stress (Minson et al. 1998) could have caused attenuation of HR changes in response to the orthostatic stress in the elderly subjects. However, we observed that the ICA blood flow in the elderly group was totally maintained with the orthostatic change despite an abolished HR response during NT. Consequently, the attenuated cardiovascular responsiveness to the orthostatic stress would not be a major mechanisms for the reduction in ICA blood flow during the dual stresses of orthostatic change and hyperthermia observed in the elderly group. Besides, the reduction in ICA blood flow might be occurred under a postural challenge with hypocapnia induced by hyperventilation as describe bellow. et al. 2015; Nelson et al. 2011). As we observed unchanged ICA and VA blood flows and 
by heat stress-induced hyperventilation, observed only in the young group (Table 2), would not

311 induce a substantial reduction in the CBF at the level of hyperthermia in the present study. On the

312 other hand, it is well-known that orthostatic stress also causes hypocapnia with hyperventilation

313 (Lucas et al. 2008; Ogoh et al. 2013; Thomas et al. 2009) and both the ICA and VA should

314 vasoconstrict during orthostatic stress. However, hypoperfusion does not occur solely because of

315 a decrease in the arterial partial pressure of $\mathrm{CO}_{2}$ and both arteries are affected differently by

316 orthostatic stress (Ogoh et al. 2015). The increased hyperventilation with orthostatic stress in the

317 young subjects compared to the elderly subjects (Table 2) would induce a significant reduction in

318 ICA blood flow especially under normothermic conditions (Figure 2). The augmented response

319 of HR and therefore CO to dual stresses in the young could compensate for the possible decrease

320 in the ICA blood flow with hyperventilation under mild hyperthermia and orthostatic stress

321 conditions. It is not clear whether cerebral $\mathrm{CO}_{2}$ reactivity is altered by the heat stress, orthostatic stress, normal aging (Bain et al. 2015; Lee et al. 2014; Ogoh et al. 2014; Oudegeest-Sander et al. 2014; Tymko et al. 2015), or a combination of these factors. We observed that the $\mathrm{P}_{\mathrm{ET}} \mathrm{CO}_{2}$ reduced markedly under both heat and orthostatic stresses in the young group. In contrast, it did not decrease under single stress of heat and orthostasis while it deceased with dual stresses of both in the elderly group. Thus, the lower arterial partial pressure of $\mathrm{CO}_{2}$ observed under heat and orthostatic exposure in the elderly could be one of the factors that induces a reduction in ICA blood flow.

The blood flow through the ICA, which supplies a large portion of the anterior brain, and the VA, which nourishes posterior brain, are affected differently by the increased body temperatures (Bain et al. 2013; Ogoh et al. 2013b) and by orthostatic stress (Ogoh et al. 2015; Sato et al. 2012). We reported that blood flow in the VA remained unchanged both with the orthostatic and heat stresses and with dual stresses of those, different from the response in the ICA (Figure 2). Our observations differ from other studies reported that the ICA and VA blood flow reduced with mild $\left(1.4^{\circ} \mathrm{C}\right)$ to severe $\left(2^{\circ} \mathrm{C}\right)$ hyperthermia similar extent or more prominently in the VA (Bain et al. 
2013; Ogoh et al. 2013b). The discrepancy appears to be related to the intensity of hyperthermia.

337 Conversely, our observations support previous studies reporting unchanged blood flow in the VA

338 during orthostatic stress by head-up tilt (Sato et al. 2012) or by lower body negative pressure

339 (Ogoh et al. 2015). Experimentally, the mean vessel diameter in the ICA was decreased in the

340 sitting position compared with the supine position while it in the VA remained unchanged (Table

341 3). The reduction in the ICA diameter was related to the hydrostatic pressure difference between body positions (Sato et al. 2012). The unchanged diameter of the VA with orthostatic stress would be explained by a difference in mechanical properties of the vessels for a change in hydrostatic pressure compared to the ICA (Sato et al. 2012), or $\mathrm{CO}_{2}$ reactivity (Ogoh et al. 2015). In addition, it has been reported that dynamic cerebral autoregulation was not impaired with mild heat stress (Low et al. 2009) and was not altered with healthy aging (Oudegeest-Sander et al. 2014), however dynamic cerebral autoregulation might be impaired with dual stresses of orthostatic challenge and hyperthermia with combination of aging. Nonetheless, we have not assess $\mathrm{CO}_{2}$ reactivity nor dynamic cerebral autoregulation in the present study. Given the low subject numbers collected for the VA, further investigations in this artery would be required to elucidate the mechanisms for the different response between arteries.

Heat stress modified the blood flow distribution due to a large increase in skin blood flow for thermoregulation (Kenney and Anderson 1988). The ECA supplies superficial regions of the head and is associated with the thermoregulatory control of skin blood flow (Ogoh et al. 2013a). Blood flow to the ECA and ICA originate from the common carotid artery. Therefore, a large increase in the ECA blood flow causes a decline in the ICA blood flow. Importantly, although thermoregulatory control of skin blood flow is known to decrease with aging, there are sitespecific differences in the decline, i.e., the sweat rate and blood flow to the skin of the forehead in elderly individuals is similar to young individuals (Inoue et al. 1991; Smith et al. 2013). Evidently, the response to increased ECA blood flow from mild hyperthermia was similar between the elderly and the young groups regardless of the orthostatic changes (Figure 2). Thus, the 
response in the ECA blood flow to the heat both at the supine and sitting positions was not enhanced but was maintained with normal aging, and thus would not cause a reduction in the ICA blood flow under mild hyperthermia and postural changes, as was observed in the elderly subjects. The present study indicates that the CBF in aged but healthy individuals is impaired under the dual stresses of heat and orthostatic changes, even if these stresses are mild and would not induce substantial changes in the CBF as single stressors, those of which would happen and be familiar in daily life. The elderly may be particularly susceptible to cerebral thrombosis, syncope, and ischemia in these situations. Indeed, marked elevations in mortality among the elderly during heat waves have been thoroughly documented (Kenney et al. 2014). Therefore, countermeasures to prevent decreases in the CBF in these situations is warranted.

\section{Limitations}

There are several potential limitations in the present study. First, the elderly and the young subjects were healthy and had no overt history of cardiovascular, metabolic, or pulmonary diseases. With advancing age, the morbidity of these diseases, which are known to decrease cardiovascular and thermoregulatory functions, generally increase (Wilson et al. 1998). Therefore, our results may underestimate the effects of aging in the general population. Second, although all the subjects were active but not engaged in any regular exercise training protocol, we have not assessed the level of physical fitness that may have a significant effect on the results, since cardiovascular and thermoregulatory responses are generally improved with the increased levels of physical fitness (Greenhaff 1989). Third, only men were included. Cardiovascular control of the circulation is generally different between the sexes (Spina et al. 1993). Therefore, the present results may not be applicable to women. Fourth, the amount of orthostatic stress associated with the postural change from the supine to the sitting position might be lower in the elderly than in the young group because of the decreased lower body vascular compliance that occurs with aging (Fu et al. 2002). This may have potentially influenced our results. Fifth concern is the validity and 
reliability of CBF measurements using ultrasonography. Ultrasonography measurements using a hand-held transducer are expected to be less reproducible because it is difficult to hold the measurement position fixed for several minutes. Furthermore, we did not use continuous assessment with advanced edge detection and wall-tracking software which greatly reduces interrater bias and variability (Bain et al. 2013; Woodman et al. 2001) in the present study. By using the software, we could assess more robust and complete quantification of the CBF. However, the coefficient of variation in the test-retest measurements for another set of subjects $(n=6)$ by the sonographer in this study was $5.2 \%$ in the ECA and were $~ 5 \%$ or less in the other arteries during the controlled supine and sitting conditions. The reproducibility of the measurement is similar to other previous studies (Sato et al. 2012). The next concern is a relatively small number of subjects. In particular, it was difficult to get reliable images for the VA blood flow assessment for some elderly subjects and only five data were obtained and included for analysis. Thus, further investigation is warranted to elucidate the difference in response between neck arteries. Lastly, the BP measurement was intermittent and not beat-by-beat in this study. Hence, it is impossible to observe beat-by beat conductance in each artery and assess the effects of baroreflex function that might potentially change with aging.

\section{CONCLUSIONS}

Our findings suggest that cerebral blood flow is impaired under the dual stresses of heat and orthostatic changes in aged but healthy individuals, even if the levels of the stresses are mild, such as in mild hyperthermia and the postural change from the supine to sitting. The present observations might explain the higher incidence of heat-related illnesses such as heat exhaustion and syncope in the elderly population. 
412 Acknowledgements

413 We are very grateful to the volunteers who participated in this study. We also thank Dr.

414 Yoshihiro Yamashina and Mr. Yoshikazu Hirasawa from our laboratory for useful comments and 415 suggestions regarding this manuscript.

416 This study was supported in part by a Grant-in-Aid for Scientific Research (C), grand 417 number 17K01656 (to A. Ota), and by a Grant-in-Aid for Scientific Research (B), grand number 418 17H03741 (to K. Okazaki) from Japan Society for the Promotion of Science.

419 The authors declare that they have no conflicts of interest.

420 


\section{References}

Ainslie PN, Cotter JD, George KP, Lucas S, Murrell C, Shave R, Thomas KN, Williams MJ, Atkinson G (2008) Elevation in cerebral blood flow velocity with aerobic fitness throughout healthy human ageing. J Physiol 586: 4005-4010

Alperin N, Lee SH, Sivaramakrishnan A, Hushek SG (2005) Quantifying the effect of posture on intracranial physiology in humans by MRI flow studies. J Magn Reson Imaging 22: 591-596

Amin-Hanjani S, Du X, Pandey DK, Thulborn KR, Charbel FT (2015) Effect of age and vascular anatomy on blood flow in major cerebral vessels. J Cereb Blood Flow Metab 35: 312-318

Bain AR, Nybo L, Ainslie PN (2015) Cerebral Vascular Control and Metabolism in Heat Stress. Compr Physiol 5: 1345-1380

Bain AR, Smith KJ, Lewis NC, Foster GE, Wildfong KW, Willie CK, Hartley GL, Cheung SS, Ainslie PN (2013) Regional changes in brain blood flow during severe passive hyperthermia: effects of PaCO2 and extracranial blood flow. J Appl Physiol 115: 653-659

Benedictus MR, Leeuwis AE, Binnewijzend MA, Kuijer JP, Scheltens P, Barkhof F, van der Flier WM, Prins ND (2017) Lower cerebral blood flow is associated with faster cognitive decline in Alzheimer's disease. Eur Radiol 27: 1169-1175

Bronzwaer AGT, Verbree J, Stok WJ, Daemen M, van Buchem MA, van Osch MJP, van Lieshout JJ (2017) Aging modifies the effect of cardiac output on middle cerebral artery blood flow velocity. Physiol Rep 5

Brothers RM, Wingo JE, Hubing KA, Crandall CG (2009) The effects of reduced end-tidal carbon dioxide tension on cerebral blood flow during heat stress. J Physiol 587: 3921-3927

Crandall CG, Levine BD, Etzel RA (1999) Effect of increasing central venous pressure during passive heating on skin blood flow. J Appl Physiol 86: 605-610

Fu Q, Iwase S, Niimi Y, Kamiya A, Michikami D, Mano T, Suzumura A (2002) Age-related influences of leg vein filling and emptying on blood volume redistribution and sympathetic reflex during lower body negative pressure in humans. Jpn J Physiol 52: 77-84

Fujii N, Tsuji B, Honda Y, Kondo N, Nishiyasu T (2015) Effect of short-term exercise-heat acclimation on ventilatory and cerebral blood flow responses to passive heating at rest in humans. J Appl Physiol 119: 435-444

Greenhaff PL (1989) Cardiovascular fitness and thermoregulation during prolonged exercise in man. Br J Sports Med 23: 109-114

Inoue Y, Nakao M, Araki T, Murakami H (1991) Regional differences in the sweating responses of older and younger men. J Appl Physiol 71: 2453-2459

Kenney WL, Anderson RK (1988) Responses of older and younger women to exercise in dry and humid heat without fluid replacement. Med Sci Sports Exerc 20: 155-160

Kenney WL, Craighead DH, Alexander LM (2014) Heat waves, aging, and human cardiovascular health. Med Sci Sports Exerc 46: 1891-1899

Lakatta EG (1993a) Deficient neuroendocrine regulation of the cardiovascular system with advancing age in healthy humans. Circulation 87: 631-636

Lakatta EG (1993b) Cardiovascular regulatory mechanisms in advanced age. Physiol Rev 73: 413-467

Lee JF, Christmas KM, Harrison ML, Hurr C, Kim K, Brothers RM (2014) Variability in orthostatic tolerance during heat stress: cerebrovascular reactivity to arterial carbon dioxide. 
Lind AR, Leithead CS, McNicol GW (1968) Cardiovascular changes during syncope induced by tilting men in the heat. J Appl Physiol 25: 268-276

Low DA, Wingo JE, Keller DM, Davis SL, Cui J, Zhang R, Crandall CG (2009) Dynamic cerebral autoregulation during passive heat stress in humans. Am J Physiol Regul Integr Comp Physiol 296: R1598-1605

Low DA, Wingo JE, Keller DM, Davis SL, Zhang R, Crandall CG (2008) Cerebrovascular responsiveness to steady-state changes in end-tidal CO2 during passive heat stress. J Appl Physiol 104: 976-981

Lucas RA, Cotter JD, Morrison S, Ainslie PN (2008) The effects of ageing and passive heating on cardiorespiratory and cerebrovascular responses to orthostatic stress in humans. Exp Physiol 93: 1104-1117

Meng L, Hou W, Chui J, Han R, Gelb AW (2015) Cardiac Output and Cerebral Blood Flow: The Integrated Regulation of Brain Perfusion in Adult Humans. Anesthesiology 123: 1198-1208

Minson CT, Wladkowski SL, Cardell AF, Pawelczyk JA, Kenney WL (1998) Age alters the cardiovascular response to direct passive heating. J Appl Physiol 84: 1323-1332

Nakata H, Miyamoto T, Ogoh S, Kakigi R, Shibasaki M (2017) Effects of acute hypoxia on human cognitive processing: a study using ERPs and SEPs. J Appl Physiol 123: 1246-1255

Nakata H, Oshiro M, Namba M, Shibasaki M (2015) Effects of passive heat stress on human somatosensory processing. Am J Physiol Regul Integr Comp Physiol 309: R1387-1396

Nelson MD, Haykowsky MJ, Stickland MK, Altamirano-Diaz LA, Willie CK, Smith KJ, Petersen SR, Ainslie PN (2011) Reductions in cerebral blood flow during passive heat stress in humans: partitioning the mechanisms. J Physiol 589: 4053-4064

Ogoh S, Brothers RM, Barnes Q, Eubank WL, Hawkins MN, Purkayastha S, A OY, Raven PB (2005) The effect of changes in cardiac output on middle cerebral artery mean blood velocity at rest and during exercise. J Physiol 569: 697-704

Ogoh S, Nakahara H, Okazaki K, Bailey DM, Miyamoto T (2013) Cerebral hypoperfusion modifies the respiratory chemoreflex during orthostatic stress. Clin Sci 125: 37-44

Ogoh S, Sato K, Nakahara H, Okazaki K, Subudhi AW, Miyamoto T (2013a) Effect of acute hypoxia on blood flow in vertebral and internal carotid arteries. Exp Physiol 98: 692-698

Ogoh S, Sato K, Okazaki K, Miyamoto T, Hirasawa A, Morimoto K, Shibasaki M (2013b) Blood flow distribution during heat stress: cerebral and systemic blood flow. J Cereb Blood Flow Metab 33: 1915-1920

Ogoh S, Sato K, Okazaki K, Miyamoto T, Hirasawa A, Sadamoto T, Shibasaki M (2015) Blood flow in internal carotid and vertebral arteries during graded lower body negative pressure in humans. Exp Physiol 100: 259-266

Ogoh S, Sato K, Okazaki K, Miyamoto T, Hirasawa A, Shibasaki M (2014) Hyperthermia modulates regional differences in cerebral blood flow to changes in CO2. J Appl Physiol 117: 46-52

Oudegeest-Sander MH, van Beek AH, Abbink K, Olde Rikkert MG, Hopman MT, Claassen JA (2014) Assessment of dynamic cerebral autoregulation and cerebrovascular CO2 reactivity in ageing by measurements of cerebral blood flow and cortical oxygenation. Exp Physiol 99: 586-598 
Parkes LM, Rashid W, Chard DT, Tofts PS (2004) Normal cerebral perfusion measurements using arterial spin labeling: reproducibility, stability, and age and gender effects. Magn Reson Med 51: 736-743

Ramanathan NL (1964) A New Weighting System for Mean Surface Temperature of the Human Body. J Appl Physiol 19: 531-533

Sato K, Fisher JP, Seifert T, Overgaard M, Secher NH, Ogoh S (2012) Blood flow in internal carotid and vertebral arteries during orthostatic stress. Exp Physiol 97: 1272-1280

Serrador JM, Hughson RL, Kowalchuk JM, Bondar RL, Gelb AW (2006) Cerebral blood flow during orthostasis: role of arterial CO2. Am J Physiol Regul Integr Comp Physiol 290: R10871093

Shibasaki M, Namba M, Oshiro M, Kakigi R, Nakata H (2017) Suppression of cognitive function in hyperthermia; From the viewpoint of executive and inhibitive cognitive processing. Sci Rep 7: 43528

Smith CJ, Alexander LM, Kenney WL (2013) Nonuniform, age-related decrements in regional sweating and skin blood flow. Am J Physiol Regul Integr Comp Physiol 305: R877-885

Sonntag WE, Eckman DM, Ingraham J, Riddle DR (2007) Regulation of Cerebrovascular Aging. In: Riddle DR (ed) Brain Aging: Models, Methods, and Mechanisms, Boca Raton (FL)

Spina RJ, Ogawa T, Kohrt WM, Martin WH, 3rd, Holloszy JO, Ehsani AA (1993) Differences in cardiovascular adaptations to endurance exercise training between older men and women. $\mathrm{J}$ Appl Physiol 75: 849-855

Tarumi T, Ayaz Khan M, Liu J, Tseng BY, Parker R, Riley J, Tinajero C, Zhang R (2014) Cerebral hemodynamics in normal aging: central artery stiffness, wave reflection, and pressure pulsatility. J Cereb Blood Flow Metab 34: 971-978

Thomas KN, Cotter JD, Galvin SD, Williams MJ, Willie CK, Ainslie PN (2009) Initial orthostatic hypotension is unrelated to orthostatic tolerance in healthy young subjects. J Appl Physiol 107: 506-517

Tymko MM, Skow RJ, MacKay CM, Day TA (2015) Steady-state tilt has no effect on cerebrovascular CO2 reactivity in anterior and posterior cerebral circulations. Exp Physiol 100: 839-851

Vaitkevicius PV, Fleg JL, Engel JH, O'Connor FC, Wright JG, Lakatta LE, Yin FC, Lakatta EG (1993) Effects of age and aerobic capacity on arterial stiffness in healthy adults. Circulation 88: $1456-1462$

Van Lieshout JJ, Wieling W, Karemaker JM, Secher NH (2003) Syncope, cerebral perfusion, and oxygenation. J Appl Physiol 94: 833-848

Wilson PW, D'Agostino RB, Levy D, Belanger AM, Silbershatz H, Kannel WB (1998) Prediction of coronary heart disease using risk factor categories. Circulation 97: 1837-1847

Wilson TE, Cui J, Zhang R, Crandall CG (2006) Heat stress reduces cerebral blood velocity and markedly impairs orthostatic tolerance in humans. Am J Physiol Regul Integr Comp Physiol 291: R1443-1448

Wilson TE, Cui J, Zhang R, Witkowski S, Crandall CG (2002) Skin cooling maintains cerebral blood flow velocity and orthostatic tolerance during tilting in heated humans. J Appl Physiol 93: 85-91

Woodman RJ, Playford DA, Watts GF, Cheetham C, Reed C, Taylor RR, Puddey IB, Beilin LJ, Burke V, Mori TA, Green D (2001) Improved analysis of brachial artery ultrasound using a 

novel edge-detection software system. J Appl Physiol 91: 929-937

552 Zhang R, Zuckerman JH, Levine BD (1998) Deterioration of cerebral autoregulation during 553 orthostatic stress: insights from the frequency domain. J Appl Physiol 85: 1113-1122 


\section{Figure legend}

$557 \quad$ Figure 1

558 Experimental protocol and the posture of subjects. The order of the measurement in each body 559 position counterbalanced (four subjects in the elderly group and four subjects in the young group 560 underwent the measurement in the supine position first, while the other subjects in each group 561 underwent the measurement in the sitting position first).

562

$563 \quad$ Figure 2

564 Blood flow in the neck arteries in the supine (Sup) and sitting positions (Sit) during normothermia 565 (NT) and mild hyperthermia (HT). ICA: internal carotid artery; ECA: external carotid artery; VA: 566 vertebral artery. Means \pm SEM for each group were shown in bar graphs with individual data. *P $567<0.05 . \mathrm{n}=9$ for the elderly and $\mathrm{n}=8$ for the young groups, except for VA, $\mathrm{n}=5$ for the elderly. 
TABLE 1. Subjects' characteristics

\begin{tabular}{lccc}
\hline & \multicolumn{2}{c}{ Elderly $(\mathrm{n}=9)$} & \multicolumn{2}{c}{ Young $(\mathrm{n}=8)$} \\
\hline Age $(\mathrm{yrs})$ & $71.3 \pm 3.0^{*}$ & $23.3 \pm 3.1$ \\
Height $(\mathrm{cm})$ & $165 \pm 7^{*}$ & $175 \pm 6$ \\
Body weight $(\mathrm{kg})$ & $61.2 \pm 3.8$ & $65.9 \pm 12.8$ \\
BMI $\left(\mathrm{kg} / \mathrm{m}^{2}\right)$ & $22.6 \pm 1.3$ & $21.3 \pm 3.2$ \\
\hline
\end{tabular}

Values are means \pm SD. $\mathrm{P}<0.05$ vs Elderly. BMI, body mass index; * $\mathrm{P}<0.05$ vs. Young. 
TABLE 2. Body temperature and cardiovascular responses in the supine and sitting positions under normothermia and mild hyperthermia

\begin{tabular}{|c|c|c|c|c|c|c|c|c|c|c|c|c|}
\hline & \multicolumn{5}{|c|}{ Elderly $(\mathrm{n}=9)$} & \multicolumn{5}{|c|}{ Young $(\mathrm{n}=8)$} & \multicolumn{2}{|r|}{ ANOVA $p$ values } \\
\hline & \multicolumn{3}{|c|}{ Normothermia } & \multicolumn{2}{|c|}{ Hyperthermia } & \multicolumn{3}{|c|}{ Normothermia } & \multicolumn{2}{|c|}{ Hyperthermia } & \multirow{2}{*}{ Interactions } & \multirow{2}{*}{ Main effects } \\
\hline & Baseline & Supine & Sitting & Supine & Sitting & Baseline & Supine & Sitting & Supine & Sitting & & \\
\hline \multicolumn{13}{|l|}{ Body temperature } \\
\hline $\mathrm{T}_{\text {es }}\left({ }^{\circ} \mathrm{C}\right)$ & $36.5 \pm 0.2$ & $36.3 \pm 0.2$ & $36.4 \pm 0.1 \dagger$ & $37.4 \pm 0.2 *$ & $37.4 \pm 0.2 *$ & $36.8 \pm 0.1$ & $36.7 \pm 0.1$ & $36.7 \pm 0.1 \dagger$ & $37.4 \pm 0.1^{*}$ & $37.5 \pm 0.1^{*}+$ & ns & heat $(\mathrm{p}<0.001)$, posture $(\mathrm{p}=0.001)$ \\
\hline $\mathrm{T}_{\mathrm{sk}}\left({ }^{\circ} \mathrm{C}\right)$ & $33.2 \pm 0.2$ & $33.1 \pm 0.4$ & $33.1 \pm 0.3$ & $35.3 \pm 0.3^{*}$ & $34.6 \pm 0.4^{*}+$ & $33.0 \pm 0.2$ & $33.3 \pm 0.4$ & $33.1 \pm 0.3$ & $34.4 \pm 0.3^{*}$ & $34.3 \pm 0.4^{*}+$ & ns & heat $(\mathrm{p}<0.001)$, posture $(\mathrm{p}=0.018)$ \\
\hline \multicolumn{13}{|c|}{ Cardiovascular response } \\
\hline HR (bpm) & $63 \pm 2$ & $61 \pm 2$ & $62 \pm 2$ & $79 \pm 3 *$ & $76 \pm 3 *$ & $62 \pm 4$ & $54 \pm 5$ & $63 \pm 4 \dagger$ & $74 \pm 4 *$ & $85 \pm 4 * \dagger$ & posture $\times$ age $(\mathrm{p}=0.002)$ & heat $(\mathrm{p}<0.001)$, posture $(\mathrm{p}=0.005)$ \\
\hline SBP (mmHg) & $126 \pm 5$ & $134 \pm 6$ & $126 \pm 6$ & $124 \pm 4$ & $121 \pm 5$ & $115 \pm 3$ & $116 \pm 4$ & $116 \pm 3$ & $119 \pm 4$ & $118 \pm 3$ & ns & ns \\
\hline DBP (mmHg) & $73 \pm 2$ & $78 \pm 3$ & $73 \pm 3$ & $77 \pm 3$ & $69 \pm 3$ & $71 \pm 3$ & $69 \pm 3$ & $69 \pm 2$ & $69 \pm 5$ & $72 \pm 2$ & posture $\times$ age $(\mathrm{p}=0.018)$ & ns \\
\hline MBP (mmHg) & $91 \pm 3$ & $97 \pm 4$ & $90 \pm 4$ & $93 \pm 3$ & $86 \pm 3$ & $86 \pm 3$ & $85 \pm 3$ & $85 \pm 2$ & $85 \pm 4$ & $88 \pm 2$ & posture $\times$ age $(\mathrm{p}=0.028)$ & ns \\
\hline $\mathrm{P}_{\mathrm{ET}} \mathrm{CO}_{2}(\mathrm{mmHg})$ & $31.5 \pm 1.2$ & $30.7 \pm 1.1 \ddagger$ & $30.1 \pm 1.1 \neq$ & $30.2 \pm 1.2 \ddagger$ & $29.0 \pm 0.7 \dagger \ddagger$ & $36.6 \pm 0.4$ & $38.3 \pm 1.2$ & $36.1 \pm 0.4 \dagger$ & $34.6 \pm 1.8^{*}$ & $32.2 \pm 1.1^{*}+$ & ns & age $(\mathrm{p}<0.001)$, heat $(\mathrm{p}=0.013)$, posture $(\mathrm{p}=0.006)$ \\
\hline
\end{tabular}

Values a ANOVA, analysis of variance. $* \mathrm{P}<0.05$ vs. Normothermia; $\uparrow \mathrm{P}<0.05$ vs. Supine; and $\neq \mathrm{P}<0.05$ vs. Young. 
TABLE 3. Mean blood flow velocity, mean vessele diameter, and conductance in the neck arteries measured in the supine and sitting positions during normothermia and mild-hyperthermia.

\begin{tabular}{|c|c|c|c|c|c|c|c|c|c|c|}
\hline & \multicolumn{4}{|c|}{ Elderly $(n=9)$} & \multicolumn{4}{|c|}{ Young $(\mathrm{n}=8)$} & \multicolumn{2}{|c|}{ ANOVA p values } \\
\hline & \multicolumn{2}{|c|}{ Normothermia } & \multicolumn{2}{|c|}{ Hyperthermia } & \multicolumn{2}{|c|}{ Normothermia } & \multicolumn{2}{|c|}{ Hyperthermia } & \multirow{2}{*}{ Interactions } & \multirow{2}{*}{ Main effects } \\
\hline & Supine & Sitting & Supine & Sitting & Supine & Sitting & Supine & Sitting & & \\
\hline \multicolumn{11}{|c|}{ Mean blood flow velocity (cm/sec) } \\
\hline ICA & $21.4 \pm 1.4$ & $20.2 \pm 1.0$ & $22.6 \pm 1.3$ & $22.0 \pm 1.2$ & $24.3 \pm 1.2$ & $22.6 \pm 1.0$ & $25.7 \pm 1.9$ & $24.4 \pm 1.1$ & ns & ns \\
\hline ECA & $14.4 \pm 1.0 \ddagger$ & $13.1 \pm 0.7 \ddagger$ & $20.5 \pm 1.2 * \ddagger$ & $19.2 \pm 1.4 * \neq$ & $18.4 \pm 1.8$ & $19.0 \pm 2.0$ & $24.8 \pm 1.5 *$ & $25.4 \pm 2.3^{*}$ & ns & heat $(\mathrm{p}<0.001)$ \\
\hline VA & $15.4 \pm 1.5 \ddagger$ & $15.0 \pm 1.5 \ddagger$ & $16.3 \pm 1.1 \neq$ & $15.9 \pm 0.8^{\ddagger}$ & $20.8 \pm 1.3$ & $20.8 \pm 0.8$ & $21.2 \pm 1.2$ & $21.4 \pm 1.4$ & ns & age $(\mathrm{p}=0.001)$ \\
\hline \multicolumn{11}{|c|}{ Mean vassel diameter (cm) } \\
\hline ICA & $0.49 \pm 0.03$ & $0.49 \pm 0.03$ & $0.49 \pm 0.03$ & $0.44 \pm 0.02 \dagger$ & $0.47 \pm 0.02$ & $0.44 \pm 0.02 \dagger$ & $0.47 \pm 0.02$ & $0.46 \pm 0.02$ & heat $\times$ age $(p=0.046)$ & posture $(\mathrm{p}=0.048)$ \\
\hline ECA & $0.38 \pm 0.03$ & $0.37 \pm 0.02$ & $0.44 \pm 0.02$ & $0.41 \pm 0.02 \dagger$ & $0.39 \pm 0.02$ & $0.40 \pm 0.03$ & $0.43 \pm 0.02$ & $0.39 \pm 0.01 \dagger$ & ns & posture $(\mathrm{p}=0.035)$ \\
\hline VA & $0.35 \pm 0.02$ & $0.35 \pm 0.02$ & $0.34 \pm 0.02$ & $0.35 \pm 0.02$ & $0.29 \pm 0.02$ & $0.28 \pm 0.02$ & $0.29 \pm 0.02$ & $0.29 \pm 0.02$ & ns & ns \\
\hline \multicolumn{11}{|c|}{ Conductance (ml min ${ }^{-1} \mathrm{mmHg}^{-1}$ ) } \\
\hline ICA & $2.58 \pm 0.39$ & $2.98 \pm 0.47$ & $2.75 \pm 0.50$ & $2.47 \pm 0.34$ & $3.55 \pm 0.22$ & $2.89 \pm 0.24$ & $3.67 \pm 0.18$ & $3.30 \pm 0.24$ & heat $\times$ posture $\times$ age $(\mathrm{p}=0.025)$ & ns \\
\hline ECA & $0.96 \pm 0.16 \ddagger$ & $1.01 \pm 0.07 \ddagger$ & $2.24 \pm 0.24^{*} \ddagger$ & $1.93 \pm 0.18^{*}$ & $1.97 \pm 0.36$ & $2.00 \pm 0.41$ & $3.05 \pm 0.31 *$ & $2.52 \pm 0.36^{*}$ & ns & heat $(\mathrm{p}<0.001)$, age $(\mathrm{p}=0.018)$ \\
\hline VA & $0.83 \pm 0.08$ & $1.04 \pm 0.12$ & $0.98 \pm 0.10$ & $1.05 \pm 0.13$ & $1.24 \pm 0.19$ & $1.13 \pm 0.12$ & $1.21 \pm 0.17$ & $1.20 \pm 0.17$ & ns & $\mathrm{ns}$ \\
\hline
\end{tabular}

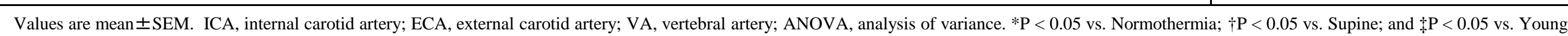
Values for VA are for 4 subjects in the elderly group, and for 6 subjects in the young group. 


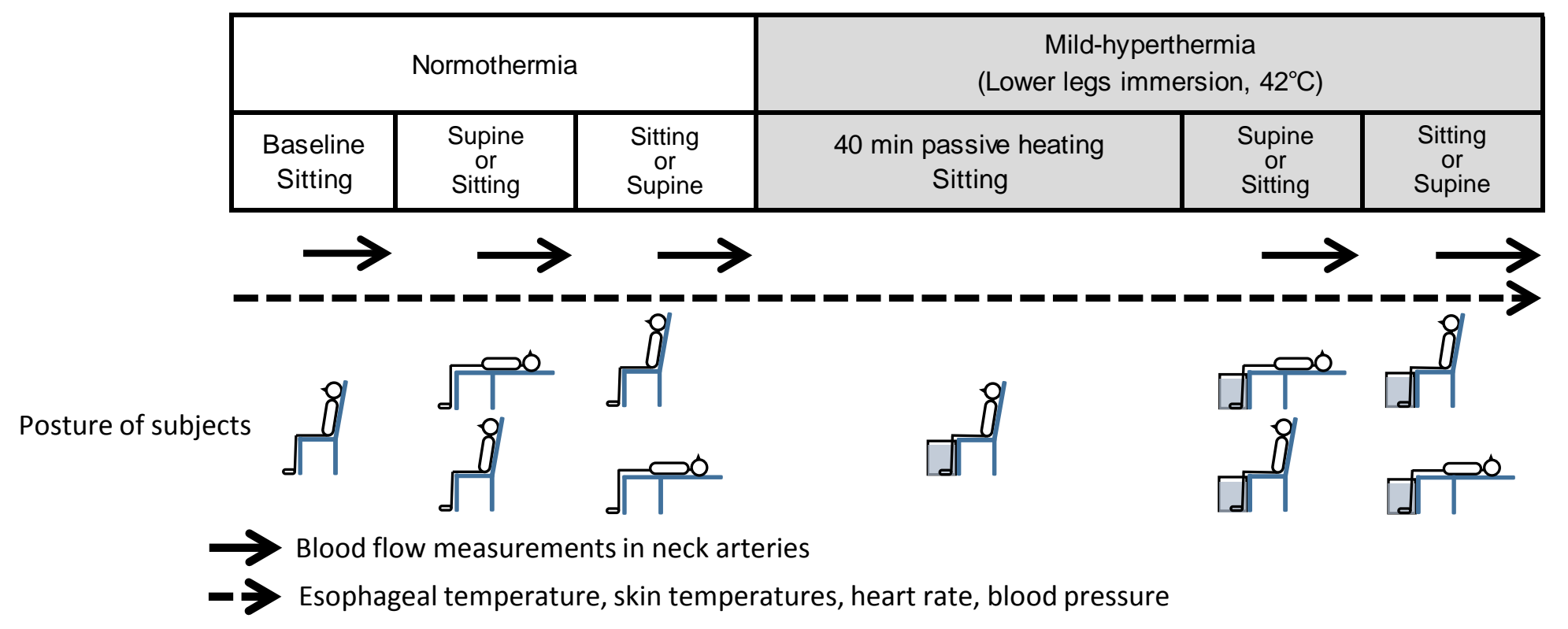

Figure 1 

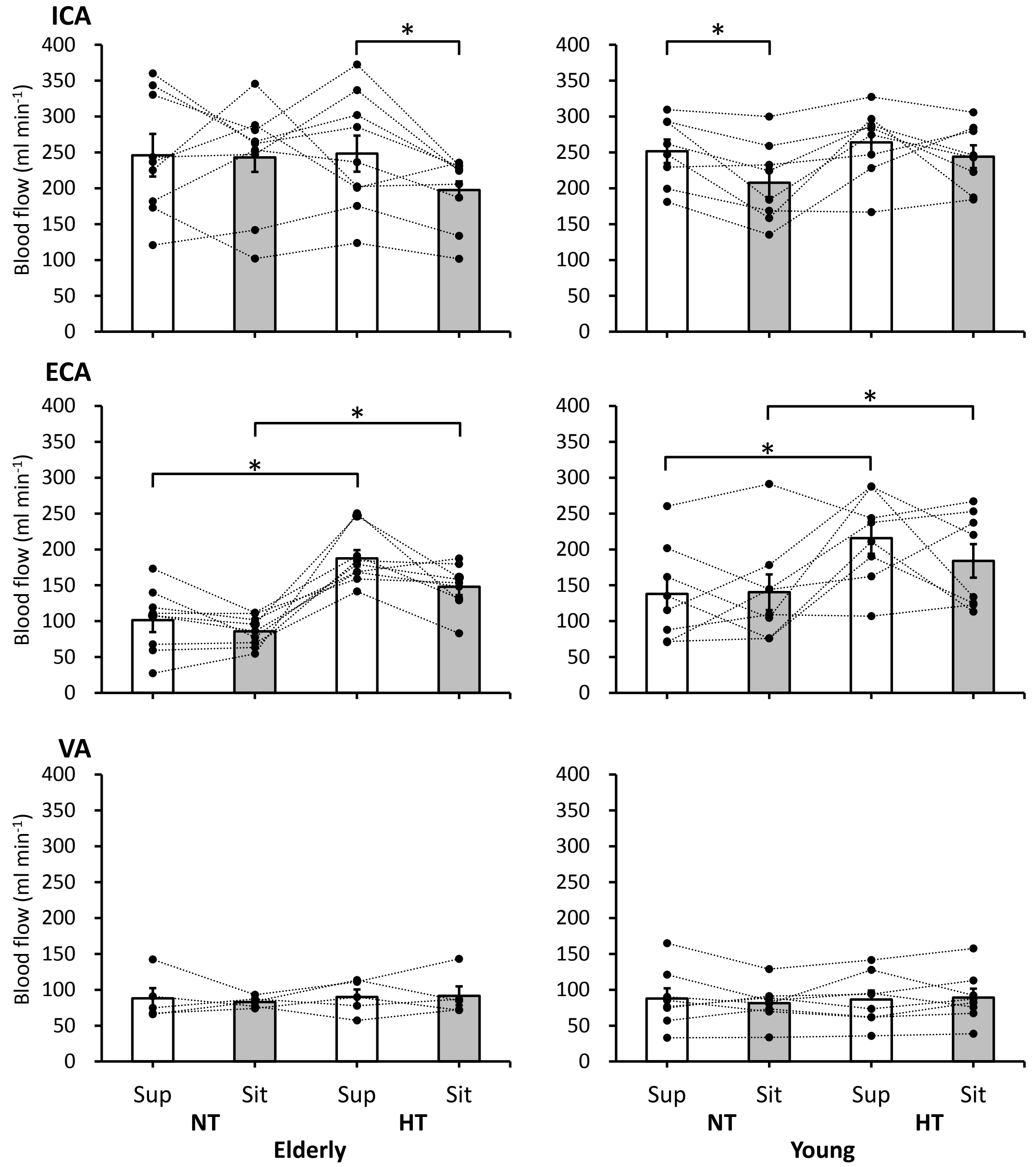

Figure 2 